\title{
Calmer waters ahead
}

\section{A conviction, the passage of a bill, and the arrival of some new committee chairmen have markedly improved the immediate outlook for biomedical research in the United States.}

T he past few years have witnessed a rough patch for relations between the US National Institutes of Health (NIH) and its overseers in Congress. Stagnant funding has followed on from the largesse that doubled the biomedical agency's budget between 1998 and 2003. Political leaders have also publicly doubted whether the \$28.6-billion agency is making the most of its windfall - and have excoriated agency officials for their allegedly lax approach to financial conflicts among its scientists (see Nature 443, 252-253; 2006).

But two events occurred last week that, between them, have the potential to mark a turning point for the world's largest research agency. On Friday, the only NIH researcher to face criminal charges over conflict-of-interest issues arising from a forthright investigation by the Los Angeles Times, subsequently followed up in Congress, pleaded guilty in a federal court (see page 803 ). His sentencing on 22 December, along with new, tighter agency rules, may begin to disperse the cloud that has been hanging over the agency as a result of the actions of a few dozen NIH researchers.

Perhaps more importantly, in the small hours of 9 December, the outgoing Congress - pushed along by Congressman Joe Barton (Republican, Texas) - passed a bill that will guide the management of the agency over the coming years (see page 796).

This 'authorization' bill sets caps that could permit further increases in the NIH budget. This is no guarantee that the money will actually be doled out by the appropriations committees in Congress. But it is, says NIH director Elias Zerhouni, "a renewed vote of confidence in the NIH and really a turning point". Zerhouni asserts that after years of wondering aloud about whether the $\mathrm{NIH}$ would deliver on its doubled budget, Congress has finally decided that the agency is doing a good job - and that it needs help to do a better one.

There are other reasons why the National Institutes of Health Reform Act of 2006 is important. Once President Bush signs the bill, the NIH will have, for the first time in 13 years, a broad, explicit and up-to-date law governing its administrative structure. The bill lays out some significant requirements that may in effect buy the agency something it has been lacking on Capitol Hill: goodwill. In particular, the bill requires the NIH director to submit biennial reports to Congress, detailing the work of its 27 institutes and centres, and justifying their priorities. It is this kind of accountability that many in Congress felt has been missing since the doubling of the budget; delivering on it will help the agency re-establish its reputation there.

At the same time, the bill establishes a 'common fund' comprising up to $5 \%$ of the agency's total budget. This will be used to fund multiinstitute research that otherwise wouldn't happen, helping the NIH keep up as biomedical science evolves at unprecedented speed.

For many biomedical researchers, funding levels represent the clearest indication of whether goodwill has been re-established. In this regard, the omens are good, particularly given the allocation of critical committee positions in the new Congress. David Obey (Democrat, Wisconsin), a long-time champion of the NIH, will be chairing the relevant subcommittee in the House of Representatives, as well as the full appropriations committee. On the Senate side, Tom Harkin (Democrat, Iowa), another long-standing NIH devotee, is set to chair the subcommittee funding the agency.

Given this sort of backing, and last week's events, it is beginning to look as if the NIH could enjoy a happier and more prosperous new year than might have been envisaged just a few months ago.

\section{An open debate}

\section{Researchers who work with animals should join the discussion on animal experimentation.}

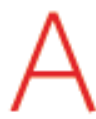
nimal research saves lives. That is the mantra often used to counter verbal and physical attacks on animal researchers and their institutions by animal-rights activists. And it is unquestionably true: animal research has made many valuable contributions to medical science.

However, the simplicity of the slogan barely does justice to the complexity of the issue. From a scientific point of view, for example, it is clear that certain animal models are useful: the neural prosthetics that promise to restore some independence to paraplegics, for example, arose from curiosity-driven studies of the primate brain (see Nature 443, 122; 2006). But others are imperfect: certain mouse models of cancer, for example, do not accurately mimic the disease in humans, and may even have hampered the development of some drugs (see Nature 442, 739-741; 2006).

In this week's issue, several articles explore what scientists really think about animal research, and what the future may hold for such work. As part of our investigation, we surveyed many of our readers in the life sciences anonymously, to solicit their views on aspects of the topic. The 1,700 or so readers who responded to our online survey are not necessarily representative of the entire community of biologists, but their responses nonetheless offer some valuable insights into the views of working scientists on questions related to animal research. The complete survey results are published on the web at www.nature.com/news/specials/animalresearch. Given the reluctance of many scientists to speak on-the-record to our reporters on this particular subject (see page 808), the exercise has been helpful in generating an overall picture of how scientists themselves view this highly contentious public issue.

Three-quarters of respondents said that animal research was 'essential' to the progress of biomedical science. However, a minority 
(fewer than one-fifth) express some misgivings about their work. "As a researcher in the field of HIV vaccine development, I am placed in a very awkward position regarding the use of non-human primates," said one immunologist. "I personally feel uncomfortable with primate research yet I realize that without primate data, vaccine candidates are rarely forwarded to human trial."

Fear is clearly a significant factor in excluding the voices of ordinary researchers from public discussion of these issues. No scientist should have to risk life and limb in order to speak about perfectly lawful work. Welcome steps have been taken by governments in both Britain and the United States to pass laws that will protect scientists under the law. And there is some evidence, in both countries, that public support for animal research has actually increased in response to animal-rights extremism.

Our survey also suggests that research agencies, universities and other institutions could do more to ensure that scientists feel free to talk about their work. There are also some indications that peer pressure is not always conducive to open communication with the public about animal research. "I am more concerned that the scientific community, rather than the animal-rights movement, makes it difficult to voice a nuanced opinion on animal research," said one neuroscientist, whose research involves using imaging to study the brains of human patients.

It is essential that researchers feel free to speak out, both within the community and beyond it, on this issue. If, as seems to be the case, scientists have made some headway in persuading the public of the value of animal research, then this is an opportune moment for them to engage in a full and open debate about the options that lie ahead - including improvements to research practice and the development of alternative approaches.

\section{The elephant in the room}

\section{A biotech trial that went awry.}

S ooner or later during the life of any drug candidate, there comes the time when it must be administered to humans. Phase I clinical trials, or 'first in man' trials, will always carry an inherent risk; the critical thing is how to manage the risk to the paid participants who volunteer as test subjects.

This is the question that a panel convened in Britain has sought to answer in the wake of the trial of TGN1412 - an antibody aimed at treating autoimmune diseases such as rheumatoid arthritis - that put six men in intensive care at London's Northwick Park Hospital in March this year (see Nature 440, 388-389; 2006). The panel was brought together to advise the Medicines and Healthcare Products Regulatory Agency (MHRA), which governs British clinical trials, on how to minimize the risks of such an event recurring.

Implicit in the list of 22 recommendations released by the panel on 7 December is an acceptance of the inherent dangers posed by some drug candidates - particularly those that target the immune system. The group's final report describes such compounds as "highriskdrugs", but makes no recommendations about when the MHRA should refuse to authorize a trial on the basis of unknown risk. Instead, the report leans towards learning as much as possible about such molecules before they are administered to people.

The panel recommends, for example, that the MHRA should consult external experts with specific knowledge of the area in question, such as a particular group of compounds. It also advocates creating a database of animal data, which might flag up adverse reactions observed previously that could otherwise be missed by regulators.

The proposals depart from the British regulator's prior practice of approving clinical trials through a process that amounted to ticking a series of boxes, towards a more subjective consideration of how drug candidates actually work. It will no longer be enough simply to demonstrate that a compound is non-toxic in an animal model.

This is to be applauded. But the fact remains that many of the drugs now being readied for clinical trials, for all their enticing potential benefits, carry risks that can never be eliminated. TGN1412, for example, was intended to bypass one of the cellular checks blocking the activation of a certain class of $\mathrm{T}$ cell. The problem was that, in humans, its activation was more widespread than expected among the different types of $\mathrm{T}$ cell, inducing a storm of inflammatory molecules that led to widespread inflammation and organ failure.

Preclinical trials in monkeys had shown no such adverse reaction, despite the fact that they share an almost identical receptor for the antibody. As part of the investigation that led to the report, immunologist Stephen Inglis of the National Institute for Biological Standards and Control near London and his colleagues developed an in vitro test using human blood cells that recreated the behaviour of the trial volunteers' cells.

Inglis and the rest of the advisory panel now advocate including such tests in future predinical evaluations of antibody drug candidates. But this test was retrospective - a team of immunologists took months to recreate something that bitter experience had shown to be possible. Using similar methods to spot dangerous compounds before they go to trial will always be an exercise in guesswork.

The panel's advice included several recommendations that should be sim-
"It will no longer be enough simply to demonstrate that a compound is non-toxic in an animal model." ple common sense. Volunteers should be dosed one by one, rather than simultaneously; doctors performing the tests should have specialist, rather than general, expertise; and trials should be carried out in dedicated centres within existing hospitals, with 24-hour emergency facilities.

All this represents necessary progress. Less satisfactory is the government's failure so far to hold anybody accountable for the Northwick Park incident. The MHRA, in a subsequent investigation, exonerated both itself and Parexel, the company that administered the trial; TeGenero, the German firm that developed the drug, has gone bust. The victims have been appallingly maimed, suffering from amputations and with bleak health prospects. They are well represented legally and will doubtless now look to the courts, rather than the regulator, to determine where responsibility for their condition lies. 